\title{
Luminescent Thermochromic Silver Iodides as Wavelength-Dependent Thermometers
}

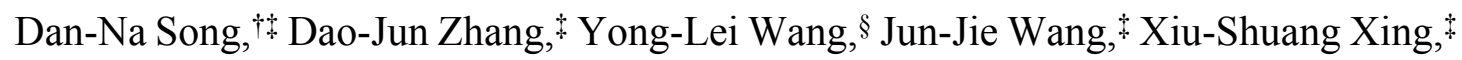

Zhi-Ying Lv, ${ }^{\ddagger}$ Fan Liu, ${ }^{\ddagger}$ Jiang-Xia Han, ${ }^{\ddagger}$ Ren-Chun Zhang, ${ }^{\ddagger *}$ Shui-Jiao Liao, ${ }^{\dagger *}$ and

Run Zhang/"

${ }^{\dagger}$ College of Basic Sciences, Huazhong Agricultural University, Wuhan 430070, Hubei, China.

Henan Province Key Laboratory of New Optoelectronic Functional Materials, College of Chemistry and Chemical Engineering, Anyang Normal University, Anyang, 455002, China.

¿Department of Materials and Environmental Chemistry, Arrhenius Laboratory, Stockholm University. SE-10691 Stockholm, Sweden.

"Australian Institute for Bioengineering and Nanotechnology, The University of Queensland, St. Lucia, Queensland 4072, Australia

Corresponding Author:

Ren-Chun Zhang: zhrenchun@sina.com

rczhang@aynu.edu.cn

Shui-JiaoLiao:liaosj@mail.hzau.edu.cn 


\section{List of contents:}

1. Characterization Methods and Calculation Details.

2. Synthesis of compounds $(\mathrm{mmIm})_{2} \mathrm{Ag}_{3} \mathrm{I}_{5}(3)$ and $(\mathrm{mmIm})_{2} \mathrm{Ag}_{2} \mathrm{I}_{4}(4)$.

3. Figures of XRD patterns.

4. Structure description of compounds 3 and 4.

5. TG curve of compounds 1 and 2.

6. Band structure and density of state of compounds 3 and 4.

7. PLE spectra of compounds 1 and 2.

8. Temperature-dependent PLE spectra of compounds 1 and 2.

9. Selected Ag-I bond lengths of compounds 1 and 2 at 100, 298 and $340 \mathrm{~K}$.

10. Reversibility test for temperature sensing. 


\section{Characterization Methods and Calculation Details.}

Characterization Methods. Powder X-ray diffraction (PXRD) analyses were carried out using an Ultima III diffractometer with $\mathrm{Cu} K \alpha$ radiation $(\lambda=1.5418 \AA)$ at room temperature. The data were collected with a scan speed of $1 \% \mathrm{~min}$ and step size of $0.02^{\circ}$, and the operating power was $40 \mathrm{kV}$ and $40 \mathrm{~mA}$. Energy-dispersive spectroscopy (EDS) was recorded on a Bruker XFlash 6130 system at $15 \mathrm{kV}$. Elemental analyses $(\mathrm{C}, \mathrm{H}$ and N) were carried out on a Vario EL III elemental analyzer. Thermogravimetric analyses (TGA) were carried out on a Netzsch STA-449F3 thermogravimetric analyzer under a flow of nitrogen $\left(40 \mathrm{~mL} \mathrm{~min}^{-1}\right)$ at a heating rate of $10{ }^{\circ} \mathrm{C} \mathrm{min}^{-1}$. The $\mathrm{UV}-$ vis reflectance spectra were measured using a Shimadazu UV-2550 double-beam, double monochromator spectrophotometer equipped with an integrating sphere, and $\mathrm{BaSO}_{4}$ plate was used as reference. Collected reflectance data were converted to the absorption data using the Kubelka-Munk functions. Photoluminescence spectra were recorded on an Edinburgh FLS-980 fluorescence spectrometer using single-photon-counting measurement. The excitation source was a $450 \mathrm{~W}$ xenon lamp. The emission lifetime was recorded at emission maximum with a $300 \mathrm{~nm}$ laser as the excitation source, and data were analyzed by exponential curve fitting. The quantum yield in the solid state was determined by an absolute method using an integrating sphere (150 mm diameter, Benflec coating) as the sample chamber. Temperature-dependent emission spectra of the compounds in the solid state were recorded, and the temperature was controlled in conjunction with a heating/cooling stage from an Oxford MercuryiTC temperature controller.

Calculation Details. The calculation of electronic band structures and density of states (DOS) were based on the density functional theory with CASTEP code. The exchangecorrelation potential was described with the Perdew-Burke-Ernzerhof (PBE) functional under the Generalized Gradient Approximation (GGA) exchange-correlation functional. The norm-conserving pseudopotential method was used for the interactions between the electrons and ions. The cutoff energy for the plane wave basis set was $765 \mathrm{eV}$, and the energy convergence tolerance was $1.0 \times 10^{-6} \mathrm{eV}$. 


\section{Synthesis of compounds $(\mathrm{mmIm})_{2} \mathrm{Ag}_{3} \mathrm{I}_{5}(3)$ and $(\mathrm{mmIm})_{2} \mathrm{Ag}_{2} \mathrm{I}_{4}(4)$}

$(\mathrm{mmIm})_{2} \mathrm{Ag}_{3} \mathrm{I}_{5}(\mathbf{3})$ : The synthesis of compound $\mathbf{3}$ is similar to that of compound $\mathbf{1}$, except mmImI (4.3 mg) was used. Colorless block crystals were obtained in 79\% yield based on AgI, and phase purity was identified by powder X-ray diffraction (Figure S3). EDS analysis on several crystals gave an average $\mathrm{Ag} / \mathrm{I}$ ratio of 3:5. Elemental analysis (\%) calc. for $3\left(\mathrm{C}_{10} \mathrm{H}_{18} \mathrm{~N}_{4} \mathrm{Ag}_{3} \mathrm{I}_{5}\right)$ : C, 10.42; H, 1.57; N, 4.86. Found: C, 10.74; H, 1.82; N, 4.59.

$(\mathrm{mmIm})_{2} \mathrm{Ag}_{2} \mathrm{I}_{4}(\mathbf{4})$ : The synthesis of compound 4 is similar to that of compound $\mathbf{1}$, except mmImI (13.3 mg) was used. Colorless prismatic crystals were obtained in $65 \%$ yield based on AgI, and phase purity was identified by powder X-ray diffraction (Figure S4). EDS analysis on several crystals gave an average $\mathrm{Ag} / \mathrm{I}$ ratio of 1:2. Elemental analysis (\%) calc. for $4\left(\mathrm{C}_{5} \mathrm{H}_{9} \mathrm{~N}_{2} \mathrm{AgI}_{2}\right)$ : C, 13.09; H, 1.98; N, 6.11. Found: C, 13.21; H,2.35; N, 5.93 .

\section{Figures of XRD patterns.}

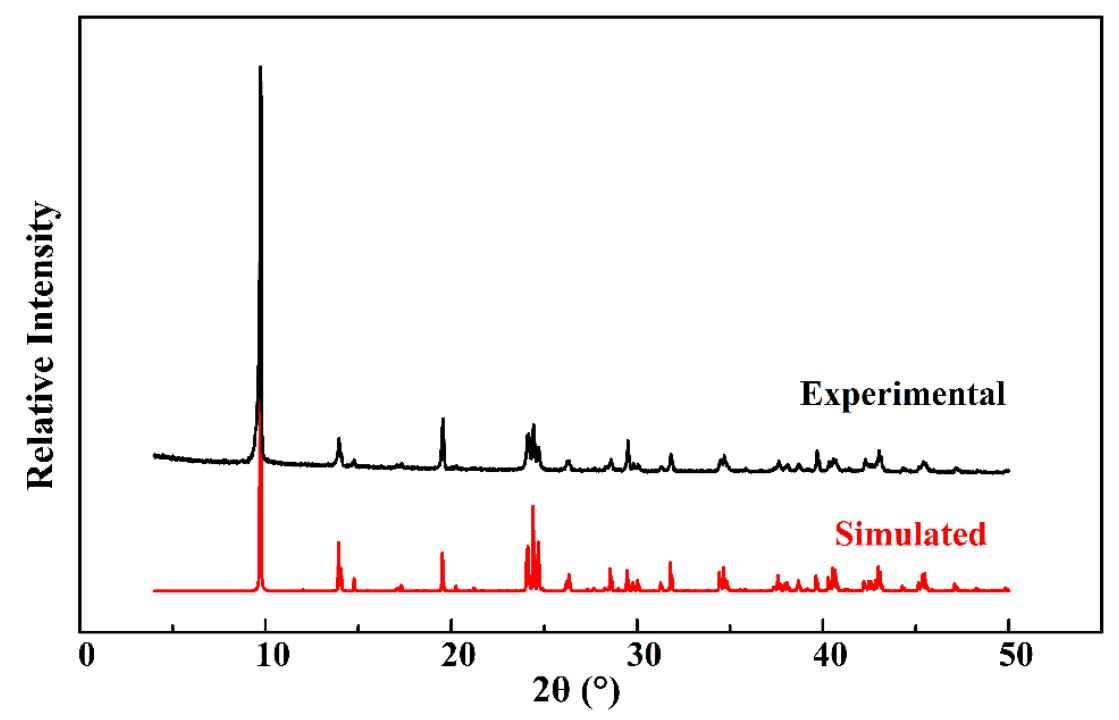

Figure S1 The experimental and simulated powder XRD pattern of the compound $\mathbf{1}$. 


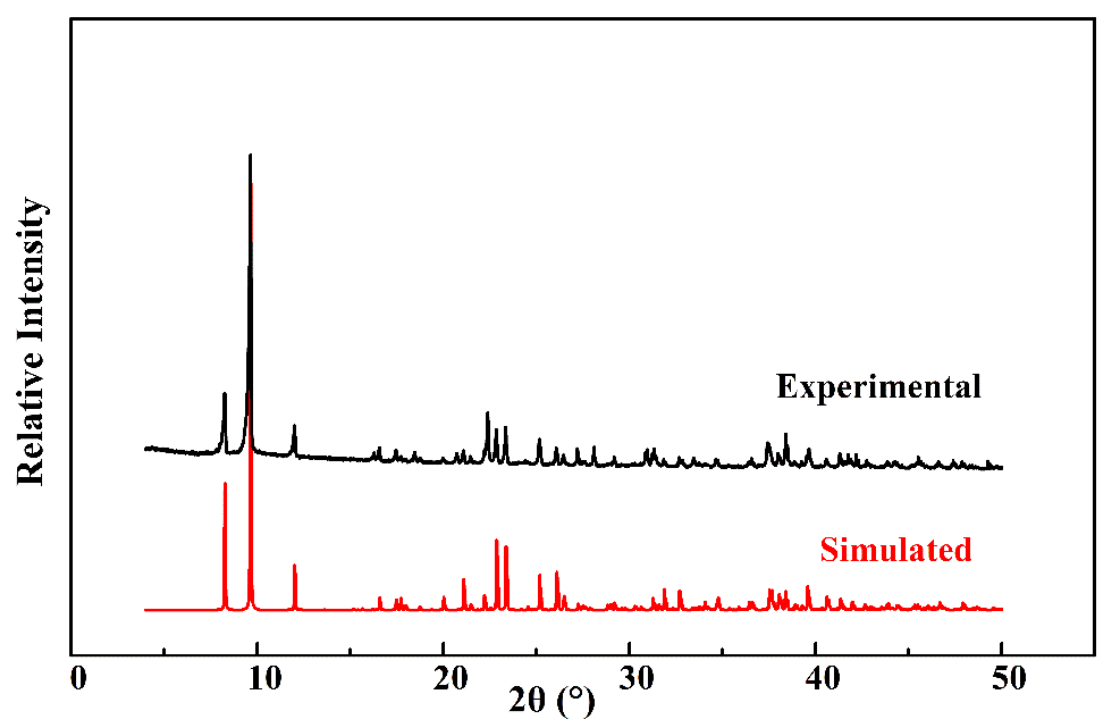

Figure S2 The experimental and simulated powder XRD pattern of the compound 2.

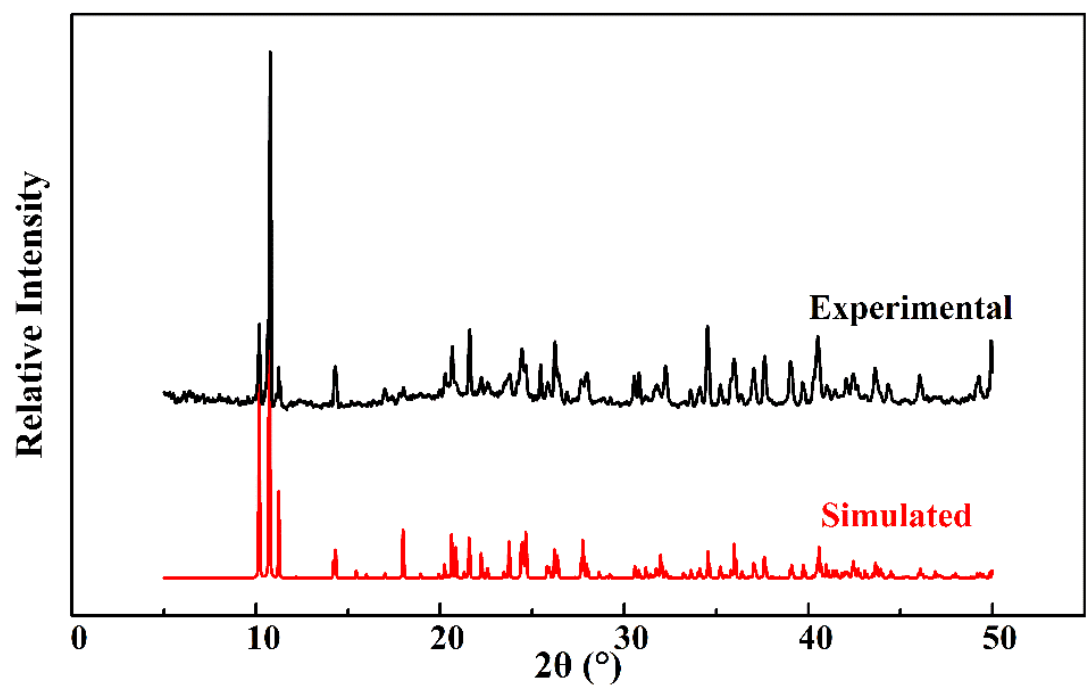

Figure S3 The experimental and simulated powder XRD pattern of the compound 3 . 


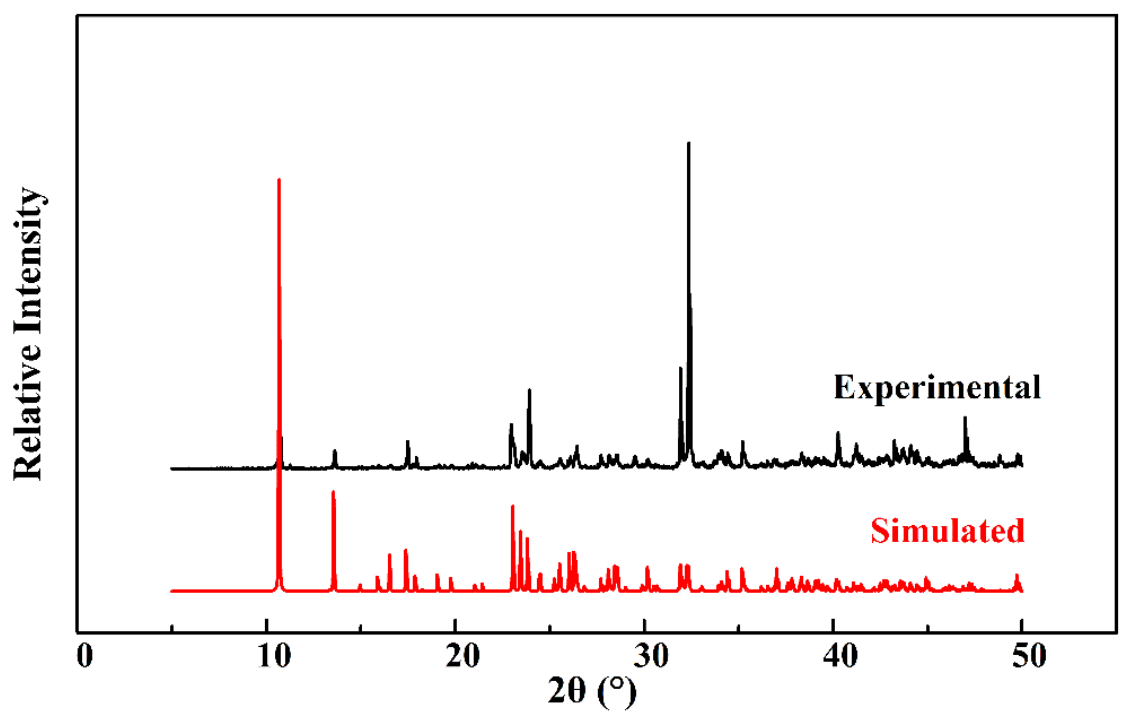

Figure S4 The experimental and simulated powder XRD pattern of the compound 4 .

\section{Structure description of compounds $(\mathrm{mmIm})_{2} \mathrm{Ag}_{3} \mathrm{I}_{5} \quad$ (3) and} $(\mathrm{mmIm})_{2} \mathrm{Ag}_{2} \mathrm{I}_{4}(4)$

Compound 3 crystallizes in the monoclinic space group $C 2 / c$ and consists of 1-D infinite $\left[\mathrm{Ag}_{3} \mathrm{I}_{5}\right]^{2-}$ anionic chain and $\mathrm{mmIm}^{+}$as counterions. As shown in the Figure S5(a). the $\mathrm{SBU}$ is a trimeric $\left[\mathrm{Ag}_{3} \mathrm{I}_{7}\right]^{4-}$ unit. In the $\left[\mathrm{Ag}_{3} \mathrm{I}_{7}\right]^{4-}$ unit, the $\mathrm{Ag}(1)$ atom is tetrahedrally coordinated, while $\operatorname{Ag}(2)$ atom is triangular coordination geometry. $\mathrm{I}^{-}$ions exhibit $\mu_{2}$ and $\mu_{3}$ two bridging modes. Thus, this $\mathrm{SBU}$ is composed of edge sharing of $\mathrm{Ag}_{2} \mathrm{I}_{6}$ dimeric unit and a trigonal $\mathrm{AgI}_{3}$ unit. The $\mathrm{Ag}$... Ag distances are ranging from 2.622(2) to 3.099(2) $\AA$, which suggesting weak M...M interactions. The trimeric $\left[\mathrm{Ag}_{3} \mathrm{I}_{7}\right]^{4-}$ unit connects to adjacent units by sharing $\mathrm{I}^{-}$ions and promoting infinite $\left[\mathrm{Ag}_{3} \mathrm{I}_{5}\right]^{2-}$ chain (Figure S5(b)). $\mathrm{mmIm}^{+}$ions are discrete and residing between the infinite $\left[\mathrm{Ag}_{3} \mathrm{I}_{5}\right]^{2-}$ anionic chain (Figure S5(c)). 


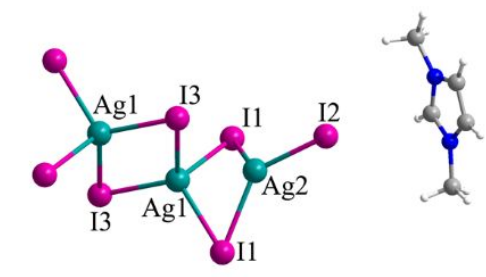

(a)

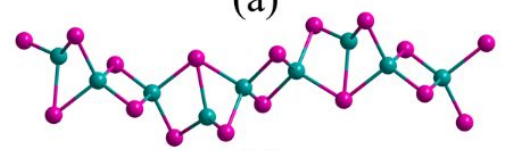

(b)

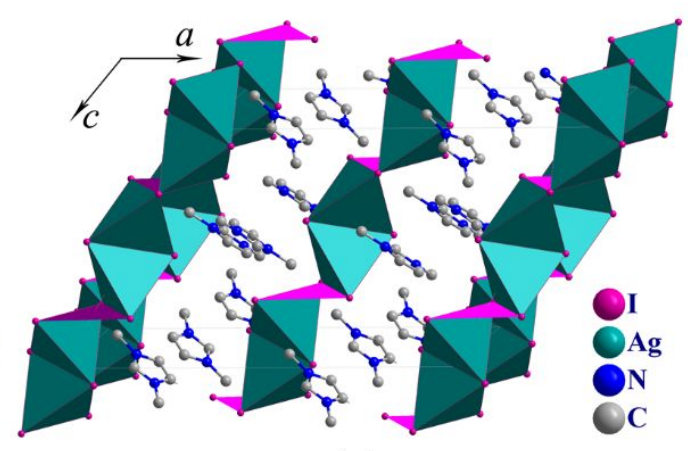

(c)

Figure S5 (a) The $\left[\mathrm{Ag}_{3} \mathrm{I}_{7}\right]^{4-}$ unit and $\mathrm{mmIm}^{+}$cation in compound 3; (b) the infinite $\left[\mathrm{Ag}_{3} \mathrm{I}_{5}\right]^{2-}$ chain in the structure; (c) polyhedral structure of structure of the compound $\mathbf{3}$.

$(\mathrm{mmIm})_{2} \mathrm{Ag}_{2} \mathrm{I}_{4}(\mathbf{4})$. Compound $\mathbf{4}$ crystallizes in the monoclinic space group $P 2_{1} / n$ and possesses 1-D infinite $\left[\mathrm{Ag}_{2} \mathrm{I}_{4}\right]^{-}$anionic chain and discrete $\mathrm{mmIm}^{+}$as counterions. In the anionic $\left[\mathrm{Ag}_{2} \mathrm{I}_{4}\right]^{-}$chain, each $\mathrm{Ag}$ atom is tetrahedrally coordinated, and the primary building unit is a $\left[\mathrm{AgI}_{4}\right]^{3-}$ tetrahedron, as shown in the Figure S6(a). By sharing edge with adjacent units, tetrahedral $\mathrm{AgI}_{4}$ units connect each other to form $\left[\mathrm{Ag}_{2} \mathrm{I}_{4}\right]^{-}$chain (Figure S6(b)). All I atoms adopt $\mu_{2}$ bridging mode. $\mathrm{mmIm}^{+}$ions are discrete and residing between the infinite $\left[\mathrm{Ag}_{2} \mathrm{I}_{4}\right]^{-}$anionic chains (Figure $\mathrm{S} 6(\mathrm{c})$ )).

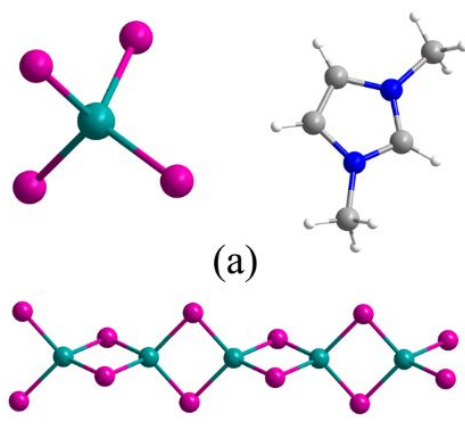

(b)

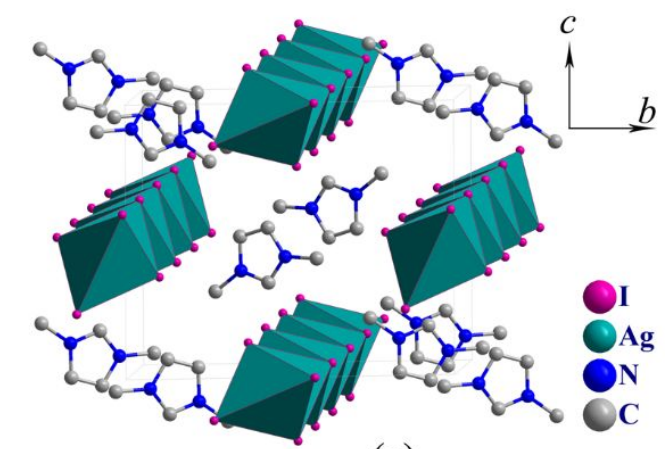

(c)

Figure S6 (a) The tetrahedral $\left[\mathrm{AgI}_{4}\right]^{3-}$ unit and $\mathrm{mmIm}^{+}$cation in compound 4; (b) the infinite $\left[\mathrm{Ag}_{2} \mathrm{I}_{4}\right]^{2-}$ chain in the structure; (c) polyhedral structure of structure of the compound 4 . 


\section{TG curves of compounds 1 and 2}

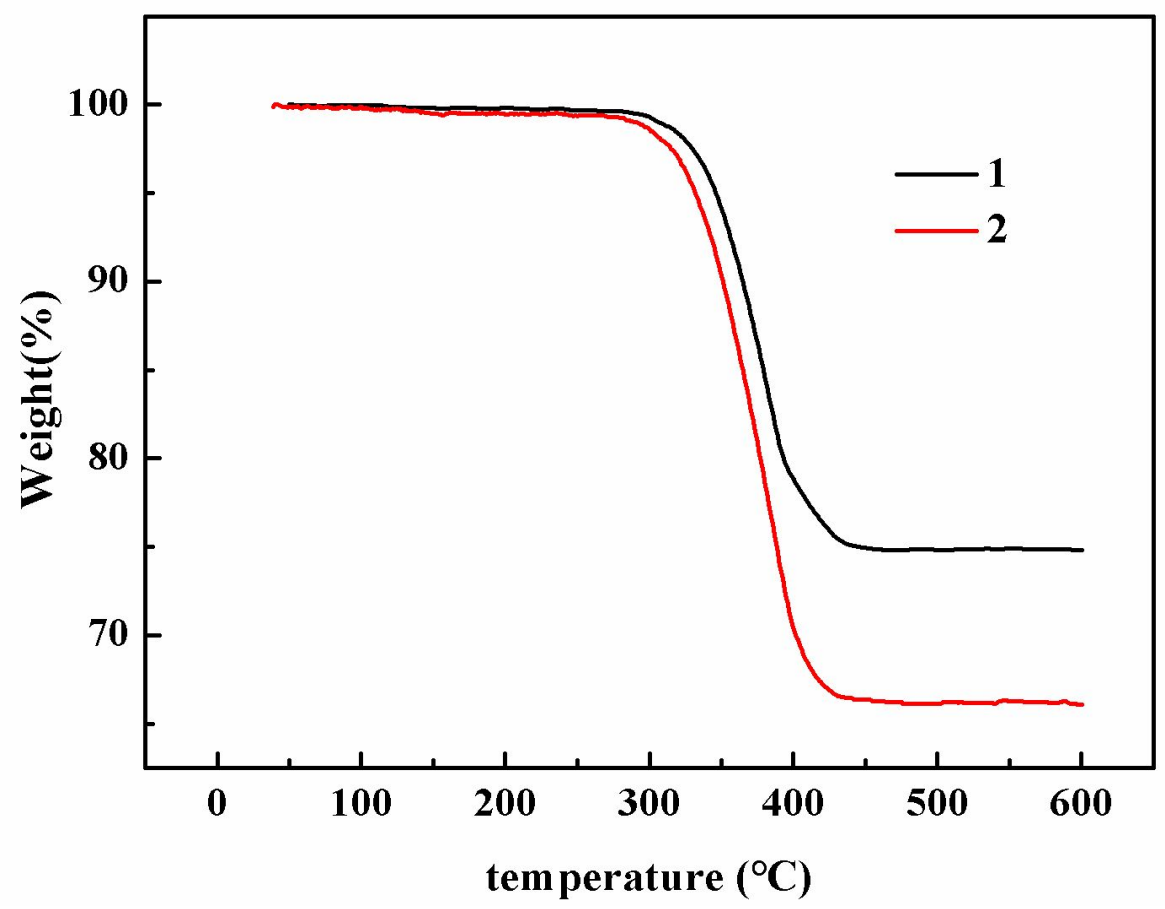

Figure S7 The thermogravimetric analysis curves of $\mathbf{1}$ and $\mathbf{2}$.

\section{Band structure and density of state of compounds 3 and 4 .}

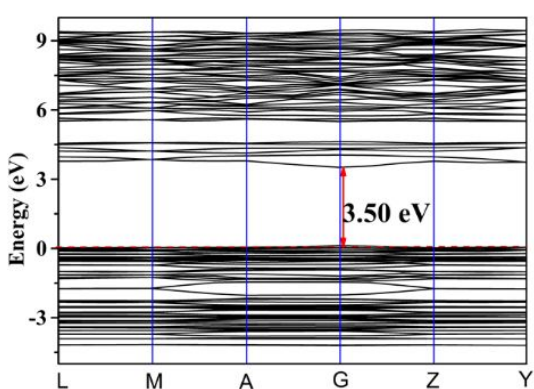

(a)

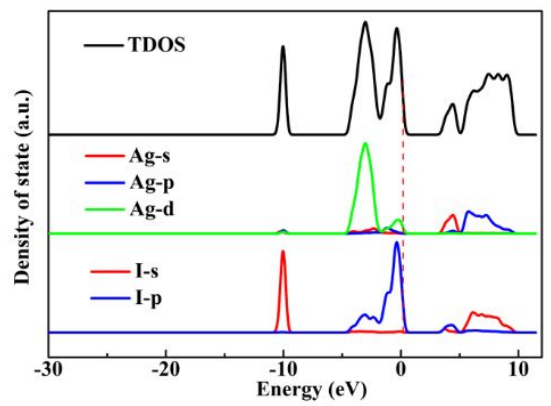

(b)

Figure S8 (a) Band structure of compound 3; (b) TDOS and PDOS of compound 3.

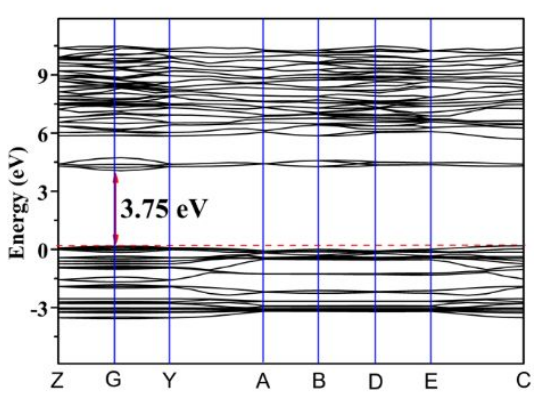

(a)

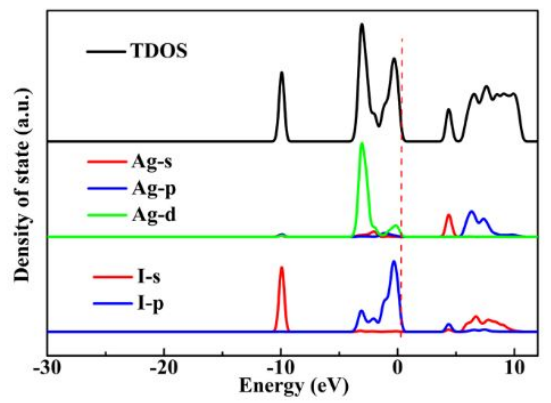

(b)

Figure S9 (a) Band structure of compound 4; (b) TDOS and PDOS of compound 4. 


\section{PLE spectra of compounds 1 and 2}

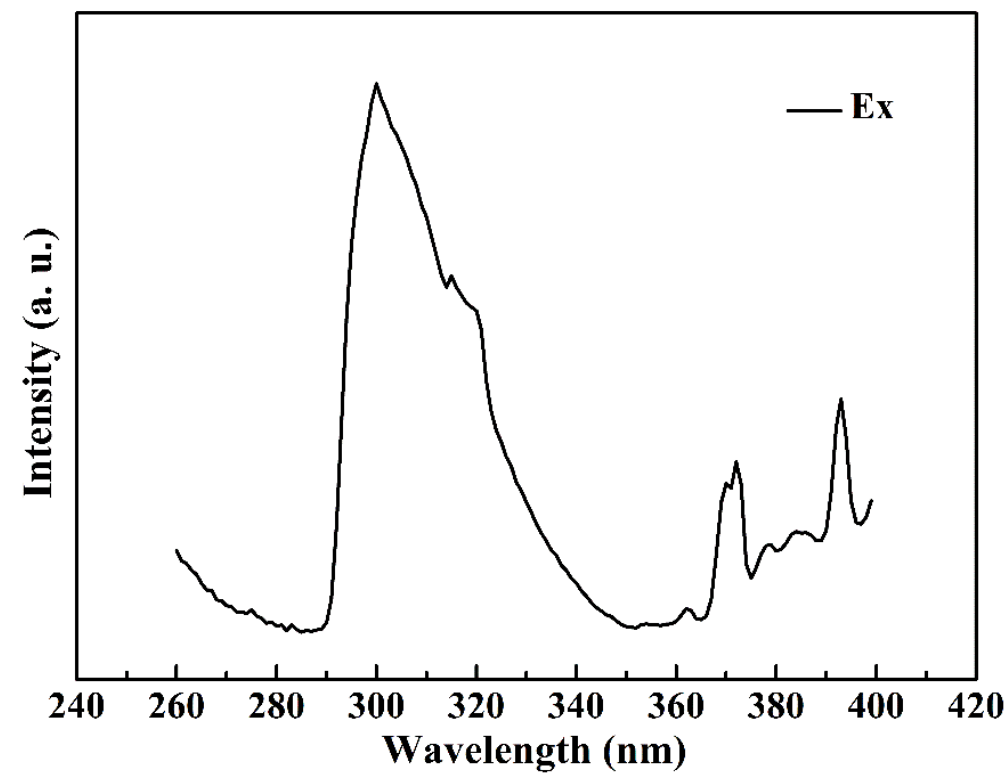

Figure S10 PLE spectrum $\left(\lambda_{\mathrm{em}}=610 \mathrm{~nm}\right)$ of compound 1 at room temperature.

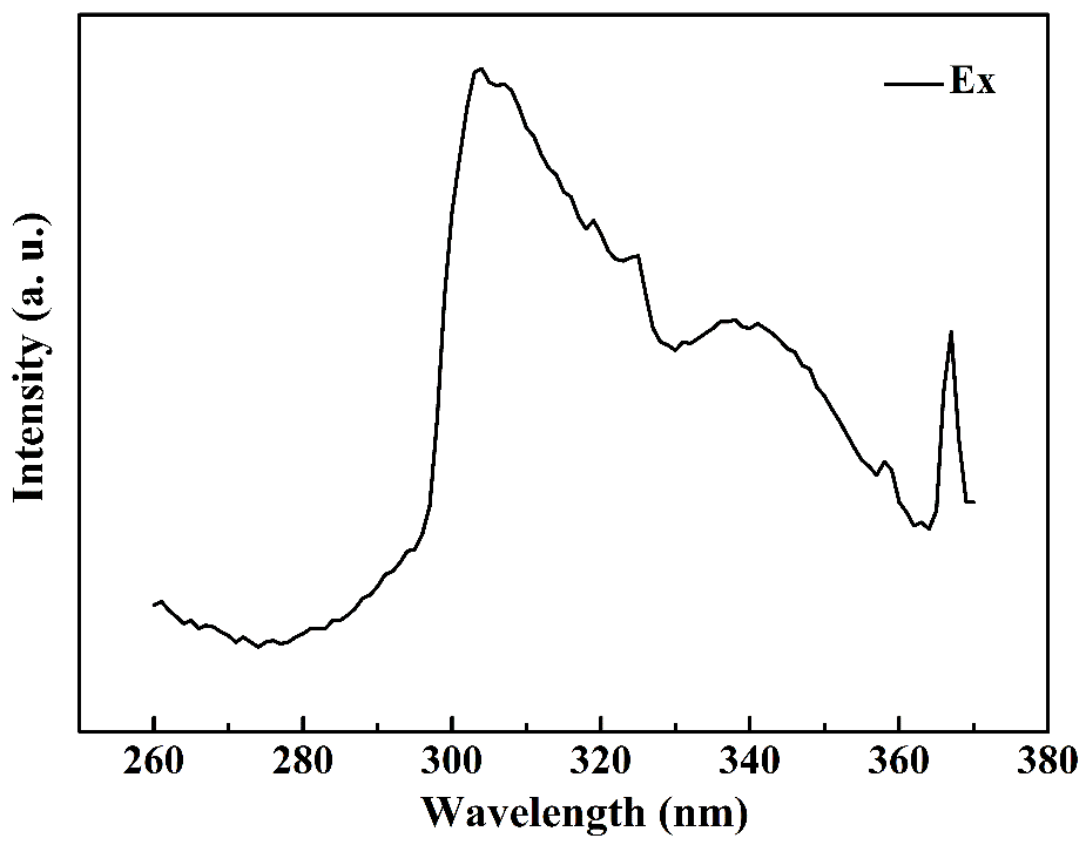

Figure S11. PLE spectrum $\left(\lambda_{\mathrm{em}}=615 \mathrm{~nm}\right)$ of compound 2 at room temperature. 


\section{Temperature-dependent PLE spectra of compounds 1 and 2.}

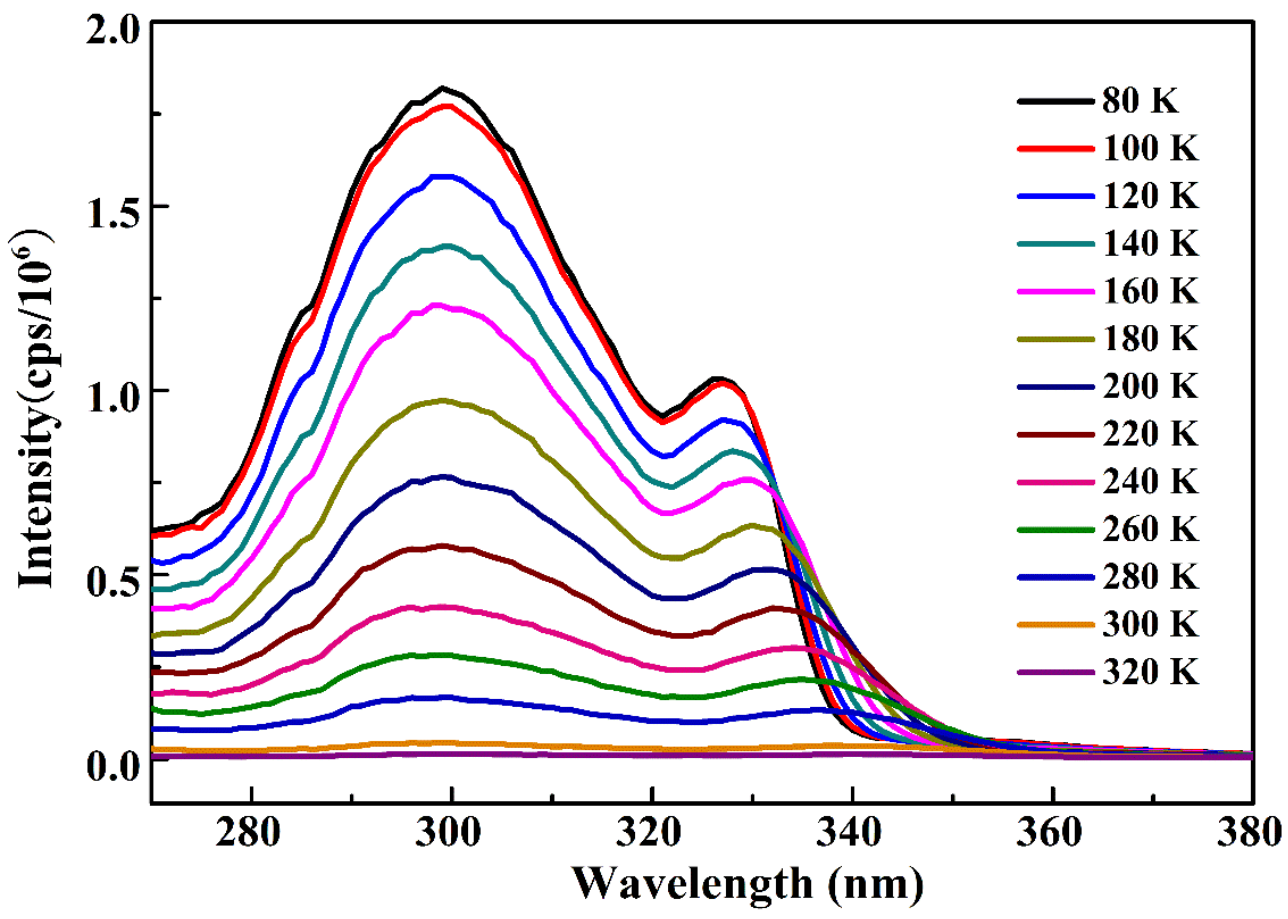

Figure S12 Temperature-dependent PLE spectra of compound 1 monitored by $768 \mathrm{~nm}$.

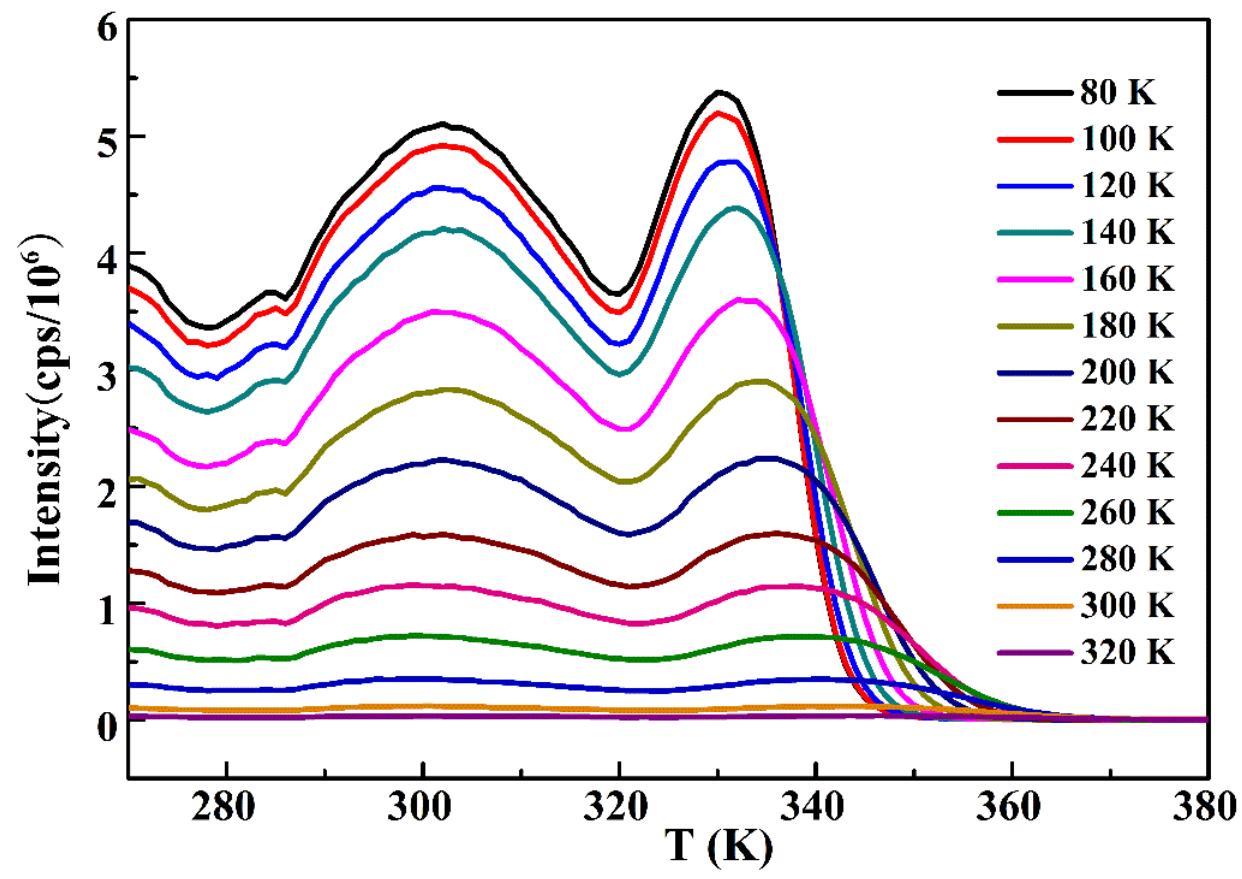

Figure S13 Temperature-dependent PLE spectra of compound 2 monitored by $774 \mathrm{~nm}$. 
9. Selected Ag-I bond lengths of compounds 1 and 2 at 100, 298 and

$340 \mathrm{~K}$.

Table S1 Ag-I bond lengths of compounds 1 at 100, 298 and 340 K

\begin{tabular}{|l|l|l|l|}
\hline \multicolumn{1}{|c|}{ Compound 1 } & \multicolumn{1}{|c|}{$\mathbf{1 0 0} \mathbf{~ K}$} & \multicolumn{1}{|c|}{$\mathbf{2 9 8} \mathbf{~ K}$} & \multicolumn{1}{c|}{$\mathbf{3 4 0}$ K } \\
\hline Bonds & & & \\
\hline Ag1-I1 & $2.876(1)$ & $2.902(2)$ & $2.903(1)$ \\
\hline Ag1-I1 & $2.905(1)$ & $2.914(2)$ & $2.914(1)$ \\
\hline Ag1-I2 & $2.832(1)$ & $2.831(2)$ & $2.829(1)$ \\
\hline Ag1-I3 & $2.820(1)$ & $2.823(2)$ & $2.821(1)$ \\
\hline Ag2-I1 & $2.899(1)$ & $2.918(2)$ & $2.916(1)$ \\
\hline Ag2-I2 & $2.825(1)$ & $2.821(2)$ & $2.820(1)$ \\
\hline Ag3-I2 & $2.822(1)$ & $2.826(2)$ & $2.824(1)$ \\
\hline Ag3-I3 & $2.835(1)$ & $2.839(2)$ & $2.840(1)$ \\
\hline Ag3-I4 & $2.877(1)$ & $2.882(2)$ & $2.883(1)$ \\
\hline Ag3-I4 & $2.881(1)$ & $2.897(2)$ & $2.895(1)$ \\
\hline Ag4-I3 & $2.852(1)$ & $2.848(2)$ & $2.849(1)$ \\
\hline Ag4-I4 & $2.894(1)$ & $2.917(2)$ & $2.917(1)$ \\
\hline Average & $\mathbf{2 . 8 6 1}$ & $\mathbf{2 . 8 7 0}$ & $\mathbf{2 . 8 6 9}$ \\
\hline
\end{tabular}

Table S2 Ag-I bond lengths of compound 2 at 100, 298 and $340 \mathrm{~K}$

\begin{tabular}{|l|l|l|l|}
\hline Compound 2 & $\mathbf{1 0 0}$ K & $\mathbf{2 9 8} \mathbf{~ K}$ & $\mathbf{3 4 0}$ K \\
\hline Ag1-I1 & $2.897(2)$ & $2.922(1)$ & $2.917(2)$. \\
\hline Ag1-I1 & $2.924(2)$ & $2.952(1)$ & $2.945(2)$ \\
\hline Ag1-I3 & $2.830(2)$ & $2.825(1)$ & $2.814(2)$ \\
\hline Ag1-I2 & $2.810(2)$ & $2.807(1)$ & $2.799(2)$ \\
\hline Ag2-I1 & $2.917(2)$ & $2.913(1)$ & $2.910(2)$ \\
\hline Ag2-I1 & $2.960(2)$ & $2.913(1)$ & $2.910(2)$ \\
\hline Ag2-I3 & $2.844(2)$ & $2.814(1)$ & $2.809(2)$ \\
\hline Ag2-I2 & $2.817(2)$ & $2.802(1)$ & $2.795(2)$ \\
\hline Average & $\mathbf{2 . 8 7 5}$ & $\mathbf{2 . 8 8 1}$ & $\mathbf{2 . 8 6 3}$ \\
\hline
\end{tabular}




\section{Reversibility test for temperature sensing.}

Three times of cooling-heating cycle between $77 \mathrm{~K}$ and $340 \mathrm{~K}$ were carried out for each compound before temperature sensing. Then two points were randomly selected to check the level of linear compliance.

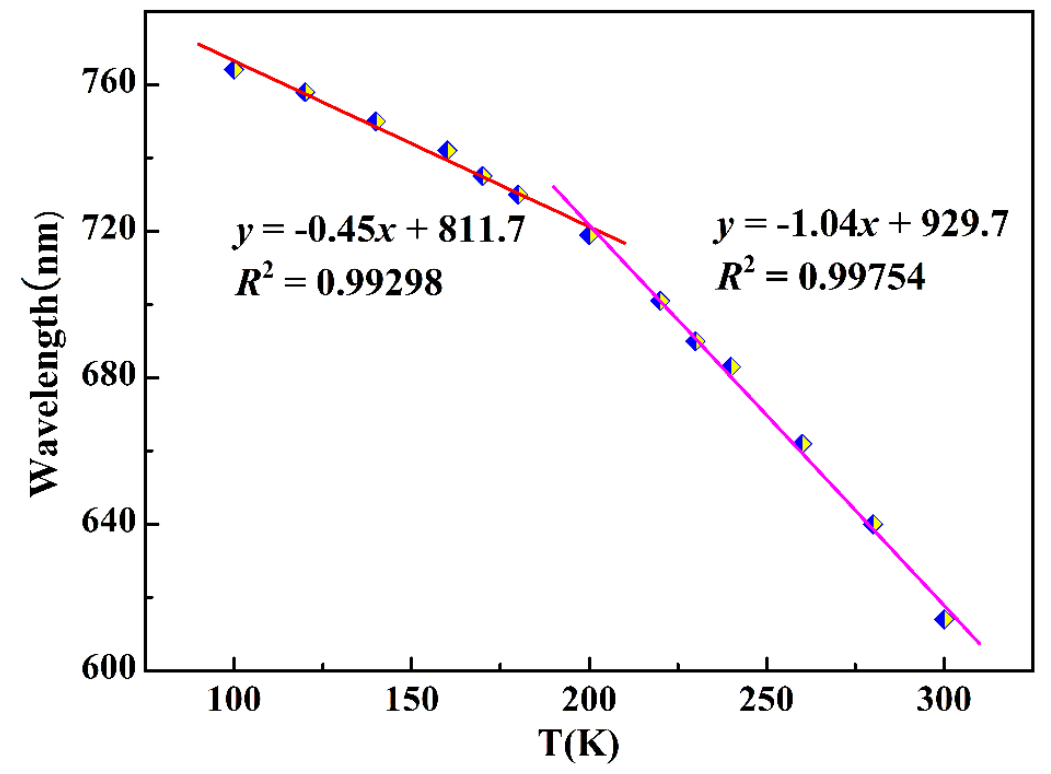

Figure S14 Two points (170K and $230 \mathrm{~K}$ ) were radomly selected to check the level of linear compliance for compound $\mathbf{1}$.

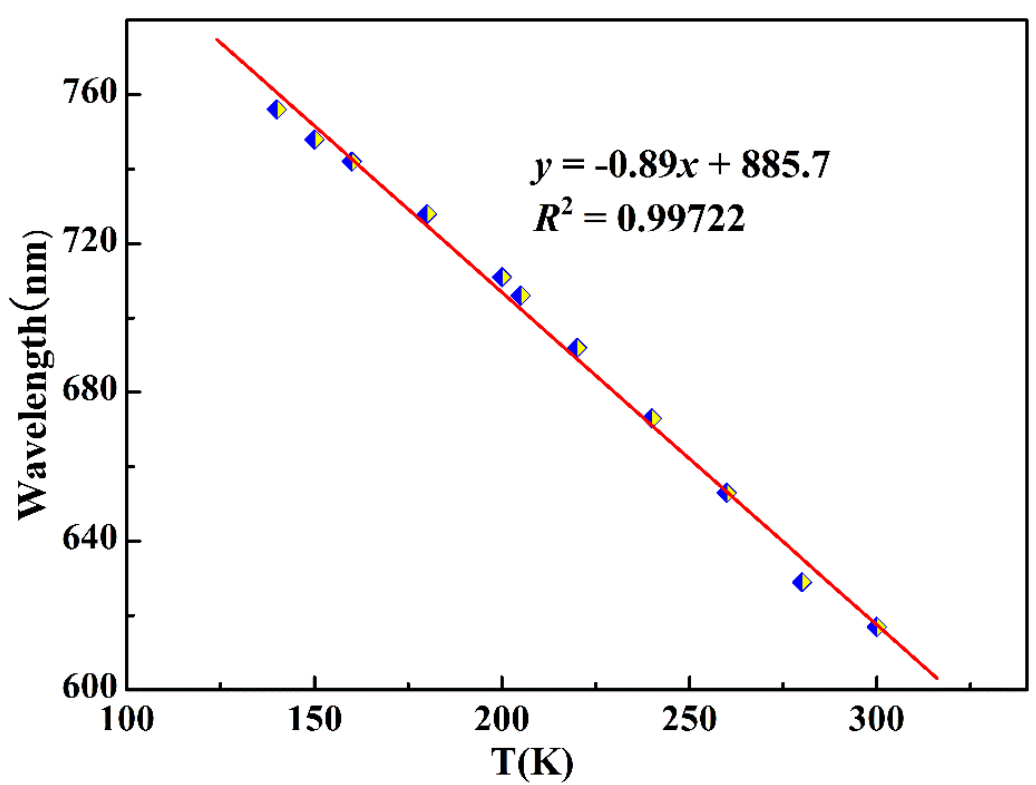

Figure S15 Two points ( $150 \mathrm{~K}$ and $205 \mathrm{~K}$ ) were radomly selected to check the level of linear compliance for compound $\mathbf{2}$. 